\begin{tabular}{|c|}
\hline $\begin{array}{c}\text { Asian Social Work Journal (ASWJ) } \\
\text { ASIAN SOCIAL WORK } \\
\text { JOURAL } \\
\text { (ASW) }\end{array}$ \\
Volume 1, Issue 1, May 2016 \\
Journal home page: \\
www.msocialwork.com \\
\hline
\end{tabular}

\title{
A Conceptual Paper on Organizational Stressors Among Higher Education Deans
}

\author{
Alfred Chan Huan Zhi ${ }^{1}$, Mohd Dahlan Hj Malek ${ }^{1}$, Ferlis Bahari ${ }^{1}$ \\ ${ }^{1}$ Universiti Malaysia Sabah \\ Corrrespondence: Alfred Chan (alfred_chz@hotmail.com)
}

\begin{abstract}
This is a conceptual paper to study the effects of organizational stressors that may impede the psychological, physiological and behavioral-interpersonal wellbeing of an organizational member. The study reviews literatures on what effects will general stress alter and degrade the psychological, physiological and behavioral-interpersonal wellbeing of an individual exposed to stressors. The final part of this study's analysis is what constitutes as organizational stressors among studies that focuses specifically on higher education deans. The factors outlined in the paper were analyzed using the theoretical framework of Managerial Stress Cycle (Gmelch, 1991) and Administrative Stress Index (Gmelch, 1982). A conceptual integrative model was developed in regard to these two frameworks. Both these models are appropriate for this inquiry because, it allows the reader to understand what are the effects of organizational stressors towards psychological and physiological health and its consequences. A number of databases such as ebcohost, springer link, science direct, Jstor and emerald were used to acquire literature on the topics. Conclusions from the literature states that health ailments stemming from stressors are evident and may function as a catalyst towards more dangerous diseases. Higher education dean's experiences with organizational stressors also seem to be evolving, incorporating new contemporary issues not seen in the past.
\end{abstract}

Key words: organizational stress, organizational stressor, higher education, dean

\section{Introduction}

Universities were traditionally considered to be low-stress work environments but more recent research indicates administrators experience high levels of occupational stress (Biron, Brun, \& Ivers, 2008; Karsli \& Baloglu, 2006; Lazaridou, Athanasoula-Reppa, \& Fris, 2008; Rasch et al., 1986, in Olson, 2012). The stressful component of holding an administrative position in a university has lead many research to believe university administrators experience high level of stress. This condition was discovered by Lazaridou, Athanasoula-Reppa, \& Fris (2008) in their study that investigated stress scores of university administrators and non-administrative workers. From their research, the mean anxiety scores for this group were found to higher than scores for other populations, indicating university administrators are more stressed than other workers when compared. Additionally, interpretation of the relationship indicated that the stress levels of university administrators remain constantly elevated over time, meaning university administrators are anxious much of the time. When demographic variables were also related to the stress levels, it was found that male and female administrators scored similarly on both state and trait anxiety. 
Deans are at the very heart of educational organizations (Wild, Ebbers, Shelley,1 \& Gmelch, 2003). It was described by the authors that the normal responsibilities of their complex and challenging positions generate stress for academic deans in university level organizations. Wild et al. (2003) stipulated that in addition to their complex and challenging tasks, the deans are being asked to respond to new demands that generate even more stress. not only do they face responsibilities to carry out the day to day business of their respective faculties, they are also an important talent pool for the future leadership of educational organizations (Shults, 2001).

Byme (1997) noted, there seems to be a long tradition of the dean's role in a university being overlooked or ignored by prior researchers. . As defined by Gmelch, Wolverton, Wolverton, and Sarros (1999), the academic deanship is the least studied and most misunderstood position in the academy. This stemmed from the drastic change of responsibilities and tenure of satisfaction, commitment and over time, deans of academic units appear to have undergone a transformation from chief academic officers to chief executive officers. Dean's role now has more emphasis placed on extramural funding, personnel decision making, and alumni relations.

\section{Purpose of Inquiry and Inquiry Questions}

This conceptual paper is intended to identify and understand what happens to a person's psychological , physiological and behavioral-interpersonal wellbeing when exposed to firstly, general stressors of any form, and secondly, organizational stressors. This paper then proceed to highlight specific organizational stressors experienced by a focused sample of higher education deans. Therefore, the inquiry question for this paper are:

1. How does an individual react psychologically, physiologically and behavior-interpersonally when exposed to organizational stressors?

2. What kind of contemporary organizational stressors does higher education dean encounter in this current time framework?

Information to the inquiry question will be based on an extended review and analysis of the literature in both the fields of organizational stressors and in the studies of higher education deans. The conceptual paper is significant because it will explore a number of negative psychological, physiological and behavioral-interpersonal detriments caused by exposure to organizational stressors. By having an understanding of the health and well being impairments caused by organizational stressors, the study will further examine and identify what actually constitutes as organizational stressors among a selective sample of higher education deans. Successful identification of organizational stressors may open up for future research to eradicate or minimize these stressors in order to improve the health and well being of higher education deans.

The current conceptual paper is delimited by several elements. Firstly, the paper reviews current literatures that are heavily based on western dean and their organizational stressors. Secondly, the theoretical framework highlight health ailments that has been so far discovered in organizations other than higher educational institutions. This paper also has its analytic restraints, as this type of paper relies on data previously collected by other researchers and not data by the author.

\section{An Integrative Conceptual Model of Managerial Stress Cycle and Administrative Stress Index.}

This conceptual paper integrates the Managerial Stress Cycle (Gmelch, 1991) and Administrative Stress Index (Gmelch, 1982), which gives a broader theoretical framework of contemporary higher education dean's organizational stressors and the consequences of such stressors. This theoretical framework states that certain stressor unique to the field of higher education can cause deans to suffer health ailments as the consequences. The Managerial Stress Cycle integrates various approaches to the 
study of stress and provides a broader perspective and clearer understanding of the stress process from a managerial perspective. This model comprises of four primary components of demands or stressors, perceptions or interpretations, response and consequences. As entailed by Gmelch (1991), the cycle begins with a set of demands or stressor which are both internal and external to the manager's work environment. The second stage if whether a demand or stressor produces a stress reaction depends on the perception of the individual. A physiological and psychological response to the perceived stressor will follow which is are harmful, threatening or challenging. The final stage, consequences, takes into account the long-range effects of stress, both due to its duration and intensity.

The second theoretical framework characterized administrative stress under fours clusters of role-based stress, task-based stress, boundary-spanning stress and conflict-mediating stress. As Kock, et al. (1982) explained, role-based stress are stressors that pertain to the administrator's role-set interactions and beliefs or attitudes about his or her role in the organization. Task-based stress, as another dimension of the model, are stressors stemming from the performance of one's day-to-day administrative tasks. The third dimension of boundary-spanning stress are stressors culminated from administrator's activities in relating the education institution to the external environment such as collective bargaining, dealing with regulatory agencies, and gaining public support for budgets. The final conflict-mediating stress involves stressors of parent/school conflicts.

Both these models are appropriate for this inquiry because it allows the reader to understand what are the effects of organizational stressors towards psychological and physiological health and its consequences. The second model will project clustered dimensions of organizational stressors experienced by educational administrators.

Figure 1: A Conceptual Integrative Model of Higher Education Dean Organizational Stressors Cycle

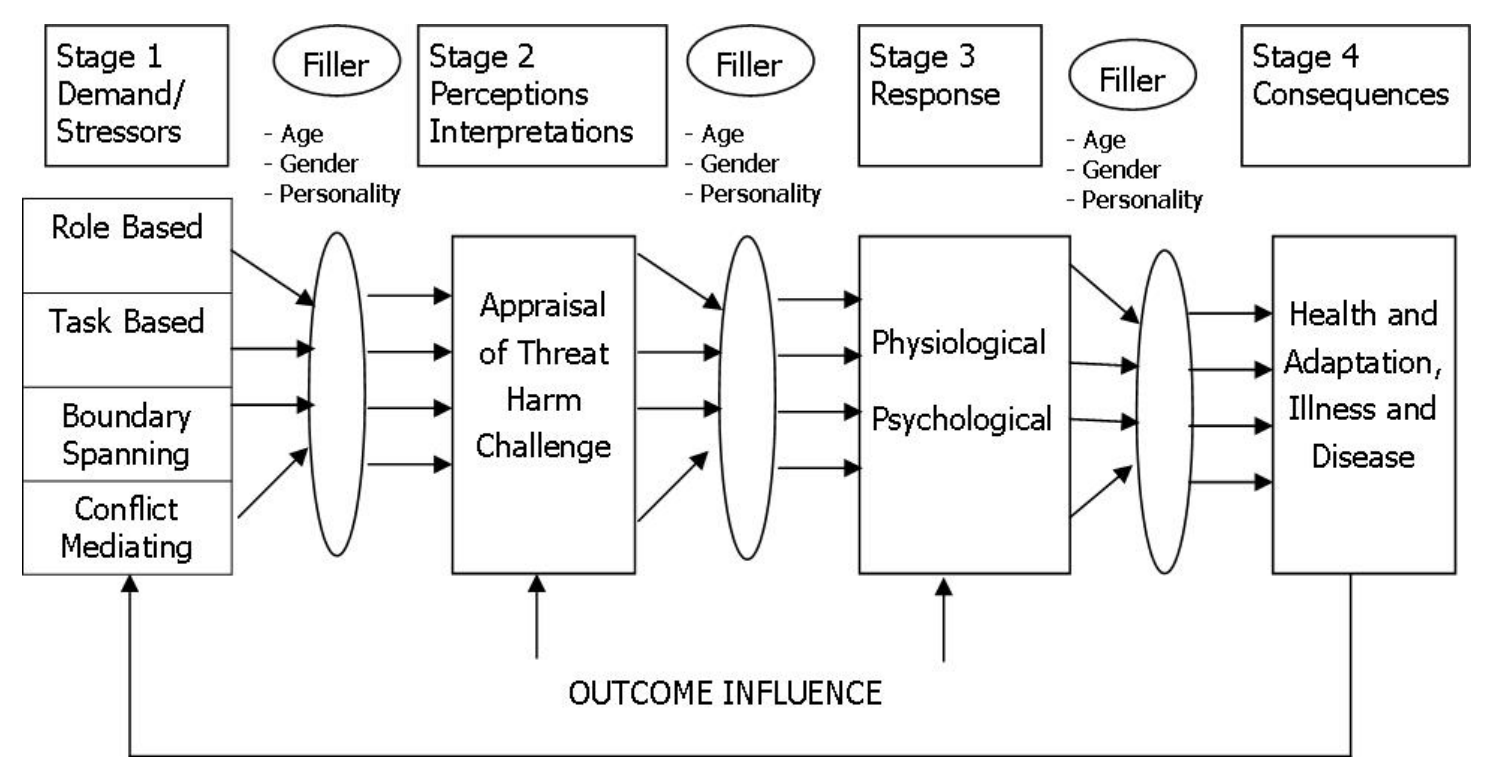

This conceptual paper has described fours approaches to organizational stressors experienced by higher education deans. The approaches consists of role based stressors, task based stressors, boundary spanning stressors and conflict mediating stressors. In addition to the causes, the subsequent cycle of the stressors were projected towards perceptions or interpretation, responses and consequences. This paper believes that the key to understanding and ultimately empirically testing these components is to create a conceptual model on integrating stressors specific to higher education deans to the overall administrative stress cycle. Further research in this area may assess on whether these components holds true in the contemporary arena of organizational stressors among higher education deans. This model is presented in Figure 1. 


\section{Psychological, Physiological and Behavioral-Interpersonal detriments from General Stress}

One of the psychological effects from experiencing stress is the diminishing effect on human memory. Remembering with great accuracy a particular emotionally arousing event is very different from performing various tasks involving memory in a day-to-day situation when one is faced with stress (Lupien, 2007). The author further described the failure of memory as such individuals may remember with great accuracy the events in their lives surrounding the World Trade Center attacks, but may also have forgotten an important appointment due to prevailing work stresses. This illustrates the declining function of memory due to stress. Stress-related intrusive thoughts also ends up competing for limited cognitive resources, thereby interfering with cognitive functioning based on a research by Mackenzie, Smith, Hasher, Leach and Behl (2007). The researchers further explain why caregivers' attentional capacity improved post-caregiving, when stress-related intrusive thoughts surely diminished.

Physiologically, the cortisol hormone is also affected when a person is suffering from stress. As acknowledged by Hellhamme., Wust. and Kudielka (2008), salivary cortisol is routinely used as a biomarker of psychological stress and related mental or physical diseases. Some ailments caused by increased cortisol levels include a suppressed immune system, insomnia, severe mood swings, depression and severe hypotension (Khandalu, 2013). Stress also increases blood pressure where Results from various studies have showed individuals who had stronger responses to stressor tasks were $21 \%$ more likely to develop blood pressure increase when compared to those with less strong responses (Gasperin, Netweli, Dias-da-costa \& Pattussi, 2009).

Individuals suffering from chronic stress also exert this ailment into their interpersonal relationship. Functioning in the social world while under a stressful condition has been documented to produce social-interpersonal impairments. Stressful behaviors may be investigated under eight different aspects of interpersonal problems such as: being overly autocratic, competitive, cold, introverted, subassertive, exploitable, expressive or nurturant (Falkum \& Vaglum, 2005). Classical works of Selye (1975) also noted that stress-related outcomes may result in exceptional interpersonal behaviors in the form of verbal and physical aggression.

\section{Psychological, Physiological and Behavioral-Interpersonal detriments from Organizational Stress}

The experience of organizational stress can cause unusual and dysfunctional mental attributes that may be detrimental to a person overall health. Cognition and psychology affect from prolong organizational stress have been reported to display mental distress, mental irritability, having a restless mind, having great difficulties to relax, difficulties for the mind to relax, complications to think logically, having a great hard time to make decisions both simple and complex, and a having a interest that is greatly diminished (Leka, Griffiths and Cox, 2004). Organizational stress also affects the state of mind and this disturbance to the cognition balance and calm were found more to affect women than men (Brate, 2014). In this instance, female respondents explained organizational stress has the effect to cause more worry among them.

Organizational stress may contributed towards detrimental physiological response such as increased blood pressure, increased metabolism (eg., faster heartbeat, faster respiration), decrease in protein synthesis, itnestional movement (digestion), immune and allergic response system, increased cholesterol and fatty acids in blood for energy production systems, localized inflammation (redness, swelling, heat and pain), faster blood clotting, increased production of blood sugar for energy, and increased stomach acids (Bickford, 2005). Organizational stress does affect employees physical health. In one study carried out at an university in Iran by Kesharvarz and Mohammadi (2011), organizational stress had affected a large percent of the employees where they have reported suffering from more than two times from illness such as muscle tension, nausea, vomiting and increased heart rate in a span of six months. 
Organizational stress have been known to cause behavioral problems, and these problems may manifest into interaction between people. Workers who faces great pressures continuously on the job may become highly stressed, and are susceptible to behave in a manner of nervousness, impulsivity and become far less tolerant towards others and these are easily symptoms that is atypical of aggressive behavior stemming from organizational stress (Vigoda, 2002). Long hours of work is one of the significant organizational stressor such as where a worker puts in a half day 12 hours long commitment. Such long hours, not only drains the energy of a worker, but was found to be related to employees displaying more neuroticism behavior (Liang et al., 2014).

\section{Higher Education Deans and Organization Stressors}

University deans are leaders of faculties, responsible for its academia objectives and production, student learning and progression, faculty members coordination, departmental equipments and budgets management, which are some of the responsibilities weighing on deans on a daily basis. In the 1980s, university administrators started reporting many organizational stressors which included budget management, recruitment and management of personnel, mediation of conflict, balancing, and balancing the demands of trustees, alumni, and governing agencies (Rasch, Hutchison, \& Tollefson, 1986).

Soon after 1980s, a 5 year period research that span across four states in the United States of America (Maryland, North Carolina, Florida, and Virginia) was carried out in identifying challenges facing the deans of university. Major issues the 102 deans identified were very similar to the stressors previously reported in existing literatures. Fiscal problems, remained the very top of the stressors experienced by the deans, with funding, budget cuts, declining resources cited as the primary challenges (Watba, \& Farmer, 2006).

An intercontinental study on deanship in the United States and in Australia was also successfully carried by Gmelch, et al (1999). Deans from schools of education business, liberal arts, and allied health profession participated and garnered a total of $n=822$ deans in the United States and $n=196$ deans from Australia. The top ten organizational stressors hampering American deans were discovered in the descending order; attending too many meetings, imposing excessively high expectations, having insufficient time to keep current in academics, trying to get financial support for college programs, balancing professional and personal lives, handling faculty conflicts, having too heavy workload, making tenure decisions, having frequent interruptions, and meeting report deadlines. Australian deans had reported similar results, with a slight difference in their ranking of interruptions as a much lesser stressor, but elevating balancing leadership and scholarship opportunities as belonging to the top ten stressors.

Wild, Ebbers, Shelly, \& Gmelch (2003) continued the progression of research into stress on university level deans, and through their research, it was confirmed that deans are experiencing stress from unexpected issues of accountability, scarce resources, and increased challenges with relationships between faculty and administration.

\section{Methods for Collecting and Analyzing Literature}

This conceptual paper is based solely on a review and analysis of research and data from literature. Research on five databases pertaining to the variables were examined. The databases were Ebscohost, Springer Link, Science Direct, JStor and Emerald. When the relevant variables were searched in each database, the total number of papers displayed was recorded along with, in bracket, the journals/articles that were deemed to be relevant to this conceptual paper. The relevant articles were retrieved and reviewed. Other terms were then searched and sorted in similar manner. The terms searched on each of the database are listed below along with the amount of articles that came up. 
Table 1 : Search terms, total results and, in bracket, retrieved papers/articles for each databases.

\begin{tabular}{|c|c|c|c|c|c|}
\hline \multirow[t]{2}{*}{ Terms } & Ebscohost & $\begin{array}{l}\text { Science } \\
\text { Direct }\end{array}$ & $\begin{array}{l}\text { Springer } \\
\text { Link }\end{array}$ & JSTOR & Emerald \\
\hline & $\begin{array}{l}\text { Total result } \\
\text { / (retrieved) }\end{array}$ & $\begin{array}{l}\text { Total result } \\
\text { / (retrieved) }\end{array}$ & $\begin{array}{l}\text { Total result } \\
\text { / (retrieved) }\end{array}$ & $\begin{array}{l}\text { Total result } \\
\text { / (retrieved) }\end{array}$ & $\begin{array}{l}\text { Total result } \\
\text { / (retrieved) }\end{array}$ \\
\hline Stress and cognition & $5,745 /(3)$ & $66,097(2)$ & $27,641(2)$ & $19,978(1)$ & $3,278(1)$ \\
\hline Stress and physiology & $248 /(0)$ & $55,818(1)$ & $47,290(2)$ & $55,818(2)$ & $3,148(1)$ \\
\hline Stress and behavior & $6,722(0)$ & $1,066,453(4)$ & $47,935(2)$ & $154,852(2)$ & $43,314(0)$ \\
\hline $\begin{array}{l}\text { Organization stress and } \\
\text { cognition }\end{array}$ & $8(0)$ & $24,316(3)$ & $1,001(0)$ & $9,511(0)$ & $2,835(0)$ \\
\hline $\begin{array}{l}\text { Organization stress and } \\
\text { physiology }\end{array}$ & $3(0)$ & $49,354(2)$ & $9,001(1)$ & $17,743(1)$ & $2,425(0)$ \\
\hline $\begin{array}{l}\text { Organization Stress and } \\
\text { behavior }\end{array}$ & $290(1)$ & $193,278(2)$ & $12,618(1)$ & $68,635(1)$ & $33,808(1)$ \\
\hline Dean stress & $62(0)$ & $40,191(2)$ & $3,228(1)$ & $33,194(0)$ & $2,259(0)$ \\
\hline
\end{tabular}

\section{Data Collection and Data Approaches for Future Research}

This is a conceptual paper that is based solely on the review of literatures available on the topic of organizational stressors and its psychological, physiological and behavioral-interpersonal effects. This approach is further streamlined to highlight the specific sample of higher education deans, which experiences somewhat difference organizational stressors as compared to other administrative or managerial positions.

For future research, a postpositivist qualitative approach will be warranted to obtain data on firstly, what contemporary organizational stressors do higher education dean uniquely experience, and what happens to this sample group psychologically, physiologically and behavioral-interpersonally when faced with these stressors.

A postpositivist qualitative approach will be used as a postpositivist engagement will take a scientific approach to research. Creswell (2007) associated this approach as having elements of being reductionist, logical, and having a strong emphasis on empirical data collection, cause and effect oriented, and a deterministic based on a priori theories. A qualitative approach is further advocated by Creswell (2009) having elements unavailable to quantitative-based research such as uncovering natural settings, having researchers as instruments, gaining multiple sources of data, ability to build inductive data analysis, bridging participant's meaning instead of researcher and developing emergent design as interpretive and holistic. Ritchie (2003) similarly aforementioned qualitative studies will be able to uncover phenomena that are not well defined, deeply rooted, complex, requiring specialist into intangible and sensitive matters such as higher education deans and enveloping effects of organizational stressors. These procedures will create a deeper understanding and uncover the real essence of the phenomena particularly by deans in Asian countries.

The sample population to be studied would be higher education deans, in one institution only pertaining to a case study methodology. This population would need to be holding on to a deanship post for at least 3 years to have a integrated experience with as much elements of organizational stressors as possible. A further investigation into the effects deans suffered psychologically, physiologically and behavior-interpersonally will be carried after organizational stressor identification. A sample size of 10 to 15 deans with an $80 \%$ minimal participatory rate would be sufficient.

Since future research will rely on a qualitative interviewing investigation, a thematic analysis (Braun \& Clarke, 2006) will be recommended to further provide a postpositivist thematic methodology. 


\section{Conclusion}

The current findings led this study to draw conclusions about what factors constitutes as organizational stressors for deans residing in western countries. Further findings also highlight the effects of suffering from general stress and organizational stress. There are two gaps that this conceptual paper uncovered, that is firstly, organizational stressors reported by deans are highly concentrated on western countries. There seem to be poor data that highlights organizational stressors experienced by higher education deans of Asian institutions. There may be differences between western and eastern experiences of organizational stressors which future research may attempt to uncover. Effects of organizational stressors in literatures also highlight populations that are based on western countries, and more on administrative and managerial positions. There is poor data on whether these same effects occur in Asian institutions' deans. Future studies stemming from this conceptual paper will broaden the field of organizational stressors into eastern populations, more specifically on Asia's higher education deans, and whether this sample suffers the same detriments as reported by western population studies.

\section{References}

Bickford, M. (2005). Stress in the Workplace: A General Overview of the Causes, the effects, and the Solutions. St. John's, Canada: Canadian Mental Health Association, Newfoundland and Labrador Division.

Biron, C., Brun, J., \& Ivers, H. (2008). Extent sources of occupational stress in university staff. Work, $30(4), 511-522$.

Brate, A.T. (2014). Diagnosing occupational stress in Romanian organizations. Procedia Social and Behavioral Science. 127, 559-564.

Braun, V. and Clarke, V. (2006). Using thematic analysis in psychology. Qualitative Research in Psychology,3(2), 77-101.

Byrne, J. P. (1997). Chairs and change in the evolving community college. Athens, GA: University o f Georgia.

Creswell, J.W. (2007). Qualitative Inquiry \& Research Design : Choosing the Five Approaches (2nd ed.). Thousand Oaks, CA: Sage Publication

Creswell, J.W. (2009). Research Design: Qualitative, Quantitative, and Mixed Methods Approaches (3rd ed.). Thousand Oaks, CA: Sage Publication.

Falkum, E. \& Vaglum, P. 2005. The Relationship Between Interpersonal Problems And Occupationalstress In Physicians. General Hospital Psychiatry 27: 285-291.

Gasperin D., Netweli, G., Dias-da-Costa, J.S. \& Pattussi, M.P. (2009). Effect Of Psychological Stress On Blood Pressure Increase: A Meta-Analysis Of Cohort Studies. Reports in Public Heath. 25(4): 715-726.

Gmelch, W.H. (1982). What Stresses School Administrators- and How They Cope. Paper Presented at Annual Meeting of the American Educational Research Association, Chicago, IL.

Gmelch, W.H. (1991). A Conceptual Understanding of Administrative Stress. Paper Presented at Annual Meeting of the American Educational Research Association, Chicago, IL.

Gmelch, W.H., Wolverton, M., Wolverton, M.L., \& James, C.S. (1999). The academic dean: an imperiled species searching for balance. Research in Higher Education, 40(6), 717-740.

Hellhammer, D.H., Wust, D. \& Kudielka, B.M. (2008). Salivary Cortisol as a Biomarker in Stress Research. Psychoneuroendocrinology. 34: 163-171.

Karsli, M.D., \& Baloglu, M. (2006). A description and comparison of the levels of anxiety among college administrators. Social Behavior and Personality: An International Journal, 34(6), 739746.

Keshavarz, M. \& Mohammadi, R. (2011). Occupational stress and organizational performance, case study: Iran. Social and Behavioral Science. 30,390-394.

Khandalu, P. (2013). Effects Of Cortisol On Physical And Psychological Aspects Of The Body And Effective Ways By Which One Can Reduce Stress. Berkeley Scientific Journal. 18(1): 14-16.

Koch, J.L., Gmelch, W., Tung, R., \& Swent, B. (1982). Job stress among school administrators: factorial dimensions and differential effects. Journal of Applied Psychology, 67(4), 493-499. 
Lazaridou, A., Athanasoula-Reppa, A., \& Fris, J. (2008). Stress among Greek and Cypriot university administrators: An exploratory study. Journal of Higher Education Policy and Management, 30(1), 87-98.

Leka, S., Griffiths, A. \& Cox T. (2004). Work Organization and Stress. Nottingham, United Kingdom. Protecting Workers' Health Series.

Liang, Y.W., Hsieh, Y., Lin Y.H. \& Chen W.Y. (2014). The impact of job stressors on health-related quality of life or nursing assistants in long-term care settings. Geriatric Nursing, 35, 114-119.

Lupien, S.J., Maheu, F., tu, M., Fiocco, A., \& Schramek, T.E. (2007). The Effects of Stress and Stress Hormones on Human Cognition: Implications for the Field of Brain and Cognition. Brain and Cognition. 65, 209-237.

Mackenzie, C.S., Smith, M.C., Hasher, L., Leach L. and Behl, P. (2007). Cognitive Functioning Under Stress: Evidence from Informal Caregivers of Palliative Patients. Journal of Palliative Medicine. 10(3):749-758.

Olson, J. M. (2012). The use of cortisol and HbAlc as biomarkers of stress in university administrators (Doctoral Dissertation, University of Arkansas, Arizona,

Rasch, D., Hutchison, J., \& Tollefson, N. (1986). Sources of stress among administrators at research universities. The Review of Higher Education, 9(4), 419-434.

Ritchie, J. (2003). The applications of qualitative methods to social research. In Ritchie, J., \& Lewis, J. (Eds.), Qualitative Research Practice : A Guide for Social Science Students and Researchers (pp. 24-46). Thousand Oaks, CA: Sage Publications

Selye, H. (1975). Stress without distress. New York: Signet.

Shults, C. (2001). The critical impact of impending retirements on community college leadership. Research Brief (Leadership Series No. 1). Washington, DC: American Association of Community Colleges.

Vigoda, E. 2002. Stress-Related Aftermaths To Workplace Politics: The Relationship Among Politics, Job Distress, And Aggressive Behavior In Organization. Journal of Organizational Behavior. 23, 1-21.

Watba, U., \& Farmer E. (2006).Challenges confronting community college deans. Community College Journal of Research and Practice, 30, 243-251.

Wild, L. L., Ebbers, L. H., Shelly, M. C. \& Gmelch, W., H. (2003). Stress factors and community college deans: The stresses of their role identified. Community College Review, 31(3), 1-23. 